\section{Commentary: Mitral valve annuloplasty and circumflex artery injury: are fewer stitches better?}

Vincent Chauvette, MD, Denis Bouchard, MD, PhD, Michel Pellerin, MD, and Louis P. Perrault, MD, PhD

Myocardial ischemia due to circumflex artery (LCX) occlusion or distortion following mitral valve (MV) surgery carries a poor prognosis and is associated with significant morbidity. ${ }^{1,2}$ First described in the 1960 s, this entity remains a feared complication among mitral valve surgeons despite several technical and perioperative improvements. ${ }^{3}$ In this regard, Caruso and colleagues ${ }^{4}$ should be commended for bringing new light to this issue. In a great example of bedside-to-bench-to-bedside study, their group initiated this study to better understand the underlying mechanism of LCX flow disturbance following MV surgery after experiencing 2 unusual cases presenting this complication.

Surgeons have long known that circumflex arteries may be at greater risk for potential injury during mitral valve surgery. In fact, preoperative coronarography can identify patients deemed at greater risk of injury, specifically those with a left dominance or codominance. ${ }^{5,6}$ In this study, the authors suggest that preoperative coronary computed tomography angiography (CTA) may be superior for assessing the risk of LCX injury during mitral surgery. In fact, CTA allows precise measurement of the distance between the mitral annulus and the LCX. Furthermore, compared with echocardiography, CTA is not operator-dependant. Although some may argue that this additional examination

\footnotetext{
From the Division of Cardiac Surgery, Department of Cardiac Surgery, Montreal Heart Institute, University of Montreal, Montreal, Canada.

Disclosures: The authors reported no conflicts of interest.

The Journal policy requires editors and reviewers to disclose conflicts of interest and to decline handling or reviewing manuscripts for which they may have a conflict of interest. The editors and reviewers of this article have no conflicts of interest.

Received for publication Nov 10, 2020; revisions received Nov 10, 2020; accepted for publication Nov 13, 2020; available ahead of print Dec 3, 2020.

Address for reprints: Louis P. Perrault, MD, PhD, Department of Cardiac Surgery,

Montreal Heart Institute, 5000 Blinger St, Montreal, Quebec, Canada H1T 1C8

(E-mail: louis.perrault@icm-mhi.org).

JTCVS Techniques 2021;5:31-3

2666-2507

Copyright (C) 2020 The Authors. Published by Elsevier Inc. on behalf of The American Association for Thoracic Surgery. This is an open access article under the CC BY-NCND license (http://creativecommons.org/licenses/by-nc-nd/4.0/).

https://doi.org/10.1016/j.xjtc.2020.11.007
}

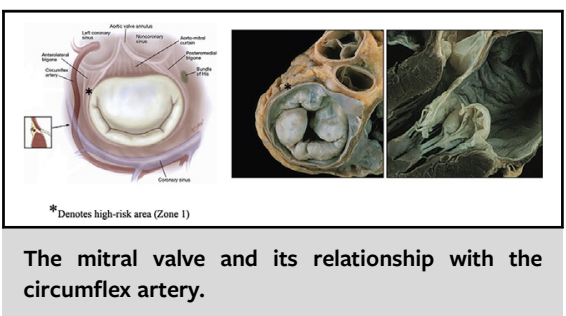

\author{
CENTRAL MESSAGE \\ Although avoiding LCX injury is \\ important, so is ensuring long- \\ term durability of MV repair. \\ Thus, it is crucial to identify pa- \\ tients who will benefit from \\ avoiding suture placement in \\ zone 1.
}

exposes patients to radiation and contrast agents, it is important to point out that most centers already order preoperative CTA when a minimally invasive mitral valve repair is contemplated. This exam provides excellent assessment of thoracic and aortoiliac vascular anatomy. Thus, rather than adding additional clinical investigation (and costs) to the preoperative workup, this study suggests an added value to the use of preoperative CTA.

Using a dedicated CTA protocol, Caruso and colleagues divided the posterior mitral annulus into 5 different zones and identified zone 1 , between the anterolateral commissure and the mid-section of P1, was the area with the greatest risk for LCX injury. Interestingly, this study also confirms that LCX dominance does indeed matter when it comes to assessing the risk of injury. In fact, the distance between the LCX and the mitral annulus was smaller in patients with a left dominance (mean, $3 \pm 2.1 \mathrm{~mm}$ ). Compared with patients with a right dominance, those with a codominance also had a shorter distance between the MV annulus and LCX $(4.6 \pm 2.3 \mathrm{~mm}$ vs $5.9 \pm 3.2 \mathrm{~mm})$. The only case of LCX distortion in this series also occurred in a patient with a left dominance.

Based on these findings, some may argue that coronary CTA should thus be reserved for patients with these specific anatomies. However, it should be noted that $>20 \%$ of patients with a right dominance also presented with "highrisk" features (distance from the LCX to the mitral annulus $<3 \mathrm{~mm}$ ). Alternatively, $75 \%$ of patients had $>3 \mathrm{~mm}$ between the LCX and mitral annulus and were deemed low risk for potential injury or distortion during mitral valve 
disease. Considering the anatomic variability of the LCX, the different anatomies require a tailored approach to minimize the incidence of complications. Whether this should include technical modifications, such as avoiding the passage of stitches in high-risk regions of the annulus, is a matter of debate. In this study, most patients with a high-risk anatomy $(50 \%)$ were treated with a flexible annuloplasty ring. A majority of those patients $(58 \%)$ even had no stitches placed in zone 1 (ie, the anterolateral commissure).

Although the authors mention that the choice of annuloplasty ring was based on the mechanism of mitral regurgitation (MR) and patient anatomy, this strategy invites some pause. According to Carpentier, the 4 principles of mitral annuloplasty consist of (1) remodeling the annulus with a 3:4 ratio between the septolateral diameter and the intercommisural diameter, (2) increasing the leaflet surface of coaptation, (3) preventing further annulus dilatation, and (4) decreasing tension on leaflets sutures. ${ }^{7,8}$ The choice of annuloplasty ring (flexible vs rigid or semirigid) in itself offers similar long-term results in degenerative mitral valve regurgitation. In ischemic MR, rigid rings may offer better durability by preventing annular dilatation ${ }^{9-11}$; however, failing to stabilize the anterolateral trigone goes against the principles of mitral annuloplasty and results in a partial annuloplasty, which has been associated with suboptimal outcomes compared with complete ring annuloplasty. ${ }^{7,12,13}$

Although the short-term results from Caruso and colleagues are reassuring in terms of MR recurrence, the follow-up in this study is still undoubtedly too short to ascertain the true impact of "incomplete annuloplasty." In fact, in studies comparing partial and complete annuloplasty, the differences in outcomes began to emerge only after 5 to 7 years of follow-up. ${ }^{13}$ In the meantime, not placing sutures in zone 1 may expose a high number of patients to suboptimal long-term outcomes. As some would say, "the cure cannot be worse than the disease." In this specific case, exposing patients to a risk of MR recurrence to avoid a rare complication may lead to more serious consequences than performing systematic complete ring annuloplasty. ${ }^{2,14}$ Although it is important to avoid LCX flow distortion, it is equally important to ensure long-term durability of MV repair. For this reason, it appears crucial to better define those patients who may benefit most from the strategy proposed in this article.

As the authors rightfully point out, preoperative assessment of coronary anatomy should outline the techniques for annular suture placement. In this regard, precise suture placement and needle orientation during annuloplasty are of the utmost importance. Specifically, avoiding deep bites and adequately alternating between forehand and backhand needle position are key technical features. In high-risk areas (zone 1; Figure 1), the needle should initially point toward the left ventricle apex, then smoothly curve toward the annulus, and finally exit $2 \mathrm{~mm}$ away from the leaflet insertion on the annulus. To this end, preoperative coronary CTA can help plan suture placement. However, it cannot assess intraoperative complications; thus, meticulous attention to technical details (eg, deairing, coronary compression leading to inadequate myocardial protection) is paramount. This is perhaps even more true in patients with a "highrisk" anatomy, in whom the threshold to reinstitute cardiopulmonary bypass and remove annuloplasty stitches may be lower, especially in the presence of a left ventricular lateral wall motion anomaly.

Finally, this study illustrates several advantages of coronary CTA and may pave the way to expand its use to other types of procedures. In fact, such interventions such as left atrial appendage ligation/closure and the maze procedure also may cause coronary artery flow distortion and myocardial ischemia. ${ }^{15-17}$ As for MV surgery, these
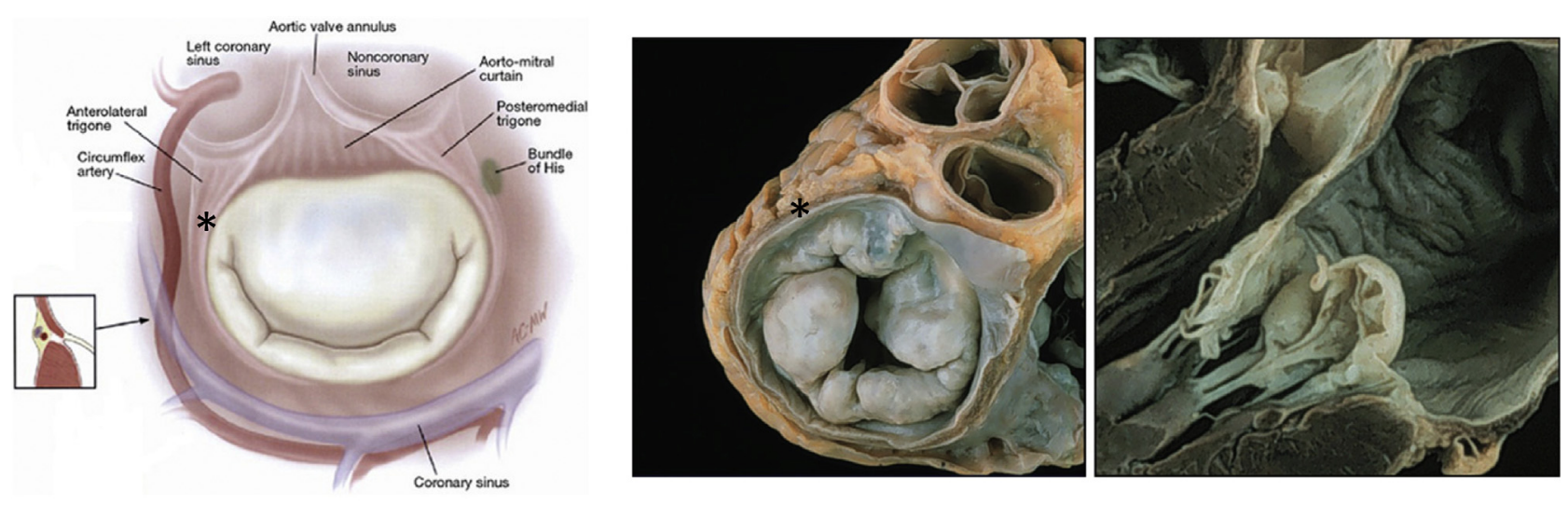

* Denotes high-risk area (Zone 1)

FIGURE 1. The mitral valve and its relationship with the circumflex artery. 
procedures require a thorough preoperative assessment of the coronary anatomy. Preoperative coronary CTA, with 3D reconstruction, provides a unique roadmap to avoid coronary injury during any given surgery. Ultimately, a multimodal approach, using preoperative coronarography and CTA, along with intraoperative echocardiography, may combine the advantages of each modality and optimize preoperative planning while also allowing intraoperative assessment of potential myocardial ischemia owing to coronary flow restriction.

This article offers important information regarding the anatomy of patients undergoing mitral annuloplasty. The authors focus on the very rare but dreadful complication associated with mitral valve surgery. Although fewer stitches may be safer, this strategy should be used sparingly, with the downside that it may lead to recurrent MR during follow-up. Future research, perhaps using postoperative coronary CTA or myocardial perfusion imaging may help better assess patients who are at elevated risk for coronary injury.

\section{References}

1. Coutinho GF, Leite F, Antunes MJ. Circumflex artery injury during mitral valve repair: not well known, perhaps not so infrequent-lessons learned from a 6-case experience. J Thorac Cardiovasc Surg. 2017;154:1613-20.

2. Aybek T, Risteski P, Miskovic A, Simon A, Dogan S, Abdel-Rahman U, et al. Seven years' experience with suture annuloplasty for mitral valve repair. $J$ Thorac Cardiovasc Surg. 2006;131:99-106.

3. Danielson GK, Cooper E, Tweeddale DN. Circumflex coronary artery injury during mitral valve replacement. Ann Thorac Surg. 1967;4:53-9.

4. Caruso V, Shah U, Sabry H, Gedela S, Birdi I. Mitral valve annulus and circumflex artery: in vivo study of anatomical zones. J Thorac Cardiovasc Surg Tech. 2020;4:122-9.
5. Hiltrop N, Bennett J, Desmet W. Circumflex coronary artery injury after mitral valve surgery: a report of four cases and comprehensive review of the literature. Catheter Cardiovasc Interv. 2017;89:78-92.

6. Bargagna M, Trumello C, Sala A, Blasio A, Castiglioni A, Alfieri O, et al. Left circumflex artery injury after mitral valve surgery: an algorithm management proposal. Ann Thorac Surg. July 31, 2020 [Epub ahead of print].

7. Carpentier AF, Lessana A, Relland JY, Belli E, Mihaileanu S, Berrebi AJ, et al. The "Physio-Ring": an advanced concept in mitral valve annuloplasty. Ann Thorac Surg. 1995;60:1177-85; discussion 1185-6.

8. Carpentier A, Adams DH, Filsoufi F. Carpentier's Reconstructive Valve Surgery: From Valve Analysis to Valve Reconstruction. Philadelphia: Saunders-Elsevier 2010

9. Chang BC, Youn YN, Ha JW, Lim SH, Hong YS, Chung N. Long-term clinical results of mitral valvuloplasty using flexible and rigid rings: a prospective and randomized study. J Thorac Cardiovasc Surg. 2007;133:995-1003.

10. Hu X, Zhao Q. Systematic evaluation of the flexible and rigid annuloplasty ring after mitral valve repair for mitral regurgitation. Eur J Cardiothorac Surg. 2011; 40:480-7.

11. Silberman S, Klutstein MW, Sabag T, Oren A, Fink D, Merin O, et al. Repair of ischemic mitral regurgitation: comparison between flexible and rigid annuloplasty rings. Ann Thorac Surg. 2009;87:1721-6; discussion 1726-7.

12. Filsoufi F, Carpentier A. Principles of reconstructive surgery in degenerative mitral valve disease. Semin Thorac Cardiovasc Surg. 2007;19:103-10.

13. Kwon MH, Lee LS, Cevasco M, Couper GS, Shekar PS, Cohn LH, et al. Recurrence of mitral regurgitation after partial versus complete mitral valve ring annuloplasty for functional mitral regurgitation. J Thorac Cardiovasc Surg. 2013;146 616-22.

14. Grande AM, Fiore A, Massetti M, Viganò M. Iatrogenic circumflex coronary lesion in mitral valve surgery: case report and review of the literature. Tex Heart Inst J. 2008;35:179-83.

15. Fayad G, Modine T, Le Tourneau T, Decoene C, Azzaoui R, Al-Ruzzeh S, et al Circumflex artery stenosis induced by intraoperative radiofrequency ablation. Ann Thorac Surg. 2003;76:1291-3.

16. Demaria RG, Pagé P, Leung TK, Dubuc M, Malo O, Carrier M, et al. Surgical radiofrequency ablation induces coronary endothelial dysfunction in porcine coronary arteries. Eur J Cardiothorac Surg. 2003;23:277-82.

17. Katona A, Temesvári A, Szatmári A, Nemes A, Forster T, Fontos G. Left circumflex coronary artery occlusion due to a left atrial appendage closure device. Postepy Kardiol Interwencyjnej. 2015;11:69-70. 